Considering there was no body to this bouncing offspring, and not an ounce of matter in it, but only a round, plump convolution of spirit or some other metaphysic manifestation or "reflection" of "immortal mind," twelve pounds on the scales was a very satisfactory result, and Mrs. Eddy ought to be proud of it. Evidently her kindly mother instinct got the start of her philosophy when she contemplated that splen. did baby. We will honor her womanly heart, even if we have to allow something off from her philosophic acumen.

For one engaged in controversy in a great theologic and medical storm-center this writer seems remarkably free from the spite and animosity common among persons thus situated. Apparently, she is genial, and seriously modifies her statements to avoid giving pain to old friends. She is weak in philosophy and logic, and her writings lack orderly arrangement, and although she calls her system "Christian Science," there is almost no science in it, according to the meaning of that word in the usage of English-speaking people. She has, however, a genius for strong and eloquent appeal to those religious feelings which are common to all mankind, and this talent is very powerful in winning favor for her medical errors.

The following is one specimen among many, of her eloquence: "For victory over one sin we give thanks, and magnify the Lord of Hosts. Then what shall we say of the mighty conquest over all sin? A louder song, sweeter than has ever before reached high Heaven, now rises clearer and nearer to the great heart of Christ; for the accuser is not there, and Love sends forth her primal and ererlasting strain." 13

CONCLUSIONS.

As a religion, Christian Science is attractive to a considerable number of persons who are dissatisfied with all other churches, whether "liberalist" or otherwise. As a philosophy, it is obscurely expressed in paradoxes and contradictions, but ornamented with many shining symbols and metaphors. It is really a species of pantheism, teaching that "God is All in All," and nothing else exists; but the authoress, moved probably by the fear of prejudice against the term "pantheism," rejects it, and shows that the German idea differs considerably from hers.

As a science, the claim for it is inadmissible, there being scarcely a trace of science in her system, in the modern sense of the word. As a therapeutic art, it helps some patients by simply encouraging them, just as all other cheering influences do, and nothing more. There are, however, great boastings about results, but no more alleged accomplishment than we always hear of in all new medical delusions. Every physician knows how each new and temporary "pathy" and "system" parades a great array of astounding cures, extending from Perkins' Tractors of last century onward to osteopathy.

Christian Science statistics do not exist in any valuable and detailed form, because the healers do not examine and diagnose diseases, but simply deny their existence. By denying the existence of matter they absolutely cut themselves off from all help from modern physical sciences. They will get over this after a while. Medical heresies mostly run one course. Starting at first with the idea of being as separate as possible, they reject all they can of the existing ideas. After a time their isolated position ceases to attract attention, their

13 Science and Health, p. 560. exclusiveness becomes mellowed, and they find they can not get on without the help of the old rejected ideas. They all come at last to this mellowing period, and finally merge back into general medicine.

I presume Christian Science healers will at last find or make some plan by which they can avail themselves of the splendid resources of the physical soiences which at present are forbidden them.

3912 Lake Avenue, Chicago.

\section{ACUTE TUBERCULAR INFECTION.}

ITS DIAGNOSIS FROM PNEUMONIA AND TYPHOID FEVER. BY H. A. HARE, M.D.

PROFESSOR OF THERAPEUTICS IN THE JEFFERSON MEDICAL COLLEGE. PHILADELPHIA.

Among the laity the word "pneumonia" is supposed to represent one definite disease, whereas among physicians a qualifying adjective, such as "croupous" or "catarrhal" is necessarily attached to it with the object of expressing a clear conception of the condition present. As a matter of fact, the word "pneumonia" in its broadest sense is simply a term which indicates consolidation of the lung which usually produces physical signs in all cases closely alike, although widely different in cause and in the consequences to the patient. It is not the intention of this paper to call attention to pneumonia in general, but to two forms of it in particular, and to deal with them not from the standpoint of treatment but from that of diagnosis and prognosis.

So much depends in each case upon the correct diagnosis for the patient's welfare and the reputation of the physician that the question is of importance. The first form of pneumonia, so-called, to which attention may be paid is that which results from typhoid infection. By this I do not refer to the complicating pulmonary lesions met with in advanced stages of the disease, but rather that condition which ushers in the attack. As Osler has well said, typhoid fever is a multiple infection in which the chief lesion of the disease may be found in other organs than the bowels, and in a larger number of cases than is thought does pneumonia begin with the attack of illness and only later does the character of the infection make itself manifest. The following case illustrates this fact very well and is one of a number which have been met with by the author:

Z., A girl, aged 10 years, was taken ill with rigor and fever, on November 10, having been well enough to be up and out of doors at dancing echool the day before. The fever speedily rose to points ranging from 103 to 105 degrees, and remained about these points for the first few days, when it gradually became a little less marked. It failed to respond readily to the use of cold spongings and the cold sheet as a rule, although at times this treatment reduced it considerably. There was but little cough, and at times none of it for two or three days, but the child was somewhat dyspneic, particularly at night, and cyanosis was marked. The pulse was usually as high as 120 to 130 , and restleseness was constant. At times, particularly at night, there was delirium. An examination of her chest revealed at the right middle lobe the physical signs of consolidation, that is, bronchial breathing, dulress on percussion and absence of vesicular sounds, with exaggerated breathing elsewhere. At the left apex similar signs were present, and it was evident that the child had pneumonia. The facial expression, the somewhat dry lips and tongue, and the color of the patient's skin, combined with the fact that pneumonia of ten is due to infection by the bacillus of Eberth, made the physician who called $m e$ in consultation and myself cautious as to the diagnosis of the case and the prognosis and, equally important, careful as to our treatment. The parents were told of the condition of the lung and of our suspicion that something other than a pure pneumonia infection was present, and we waited for the 
iday of ordinary crisis with anxiety. On November 12, the temperature fell somewhat and seemed to give promise of re. lief, but on the next it maintained its course; the tongue was found to be more enteric in appearance and the rose rash of ty. phoid fever appeared on the chest and belly. Further careful palpation at this time showed a slightly enlarged spleen and liver-an alteration in those organe not previously found - and diarrhea or rather looseness of the bowels supplanted a tendency to constipation.

Under our older ideas of those diseases it would have been thought that a primary croupous pneumonia had merged into a typhoid fever by a gradual process of developing asthenia, or again, that a double infection with the micrococous lanceolatus and the bacillus of Eberth had taken place, whereas, at the present time we know that, while such a double infection is possible, a single typhoid fever infection may result in primary pulmonary symptoms. The second condition is not far removed from that just named; indeed, it may resemble both pneumonia and typhoid fever in one case, pursuing a course similar to that just named very closely.

I refer to acute pulmonary infection by the bacillus tuberculosis. Without the error of diagnosis of typhoid fever, typhoid pneumonia or congestive chill with malarial infection is often made, when in reality tuberculosis is the cause. This is the more apt to be the case because its onset is often as sudden as is that of true croupous pneumonia, and it may arise in a patient apparently in the best of health. Thus, a man of about 30 years of age entered my wards at St. Agnes Hospital with a history of having been exposed all the previous day to a cold rain while acting as a huckster. During the night he had an exceedingly severe rigor followed by a high fever and this in turn by a drenching sweat. There was no history of illness previously, although his friends asserted that he had not looked well for some time. The entire left lobe, at the time of admission, was consolidated, and there were signs of diffuse general bronchitis all over the chest. The man died in active delirium at the end of fifteen days and the autopsy revealed widespread miliary tuberculosis.

Other cases which have not been so clearly defined might be cited in which the patient, seemingly suffering from an attack of acute pneumonia, has failed to convalesce as expected, has failed to reach a crisis, and the signs of so-called resolution of the consolidation have been really those of rapid pulmonary breakdown. In such cases, if the pulmonary signs are not frank and open, the profound asthenia into which the patient speedily passes, the diarrhea, tympanites and meteorism may lead the physician into a diagnosis of typhoid fever following pneumonia or due to the same infection as already stated.

This subject is also associated with medicolegal questions of great importance. Thus, I was recently called in a case in which a man well advanced in years was thrown from the platform of a moving street-car and struck on his side. Within a few days he devel. oped symptoms of pulmonary consolidation, became actively delirious and almost uncontrollable. He died a few days after; the postmortem showed that he had died of a pneumonia due to tubercular infection arising from low-grade chronic tubercular disease, due to the fact that he had knife-grinder's disease, from his trade. In this instance the injury broke down the protection afforded by nature to protect his lung from general infection, and the bacillus at once became an active element in the production of his death. His family sued the railroad company, whose defense was that as the disease was tuberculosis and not ordinary pneumonia, the accident was not responsible for the pulmonary change which caused his death. It was testified, however, that he might have lived for years without illness if the accident had not converted a chronic affection into an acute one, and a verdict was given for the plaintiff.

Finally, let me say a word about a possible error often committed, namely, the mistaking of tuberculasis for typhoid fever. Some time since I saw a case in consultation in which the physician stated that it was a prolonged case of enteric fever, having lasted four weeks with no sign of an approach to convales. cence. A careful examination of the patient revealed the fact that instead of being the disease named it was one of general tuberculosis, the fever, diarrhea, wasting, meteorism and general asthenia being due to this cause.

It is true that the best text-books tell us of these things, but it is also irue that only by frequent repetition can their importance be grasped and recalled at times when their recollection is vital to all concerned.

\section{GUNSHOT WOUND OF THE ABDOMEN,}

\author{
A REPORT OF FIVE CASES.
}

BY RICHARD DOUGLAS, M.D. NASHYILLE, TENN.

In the Journal of the American Medical Asso. ciation of Nov. 19, 1898, Dr. Senn reports four laparotomies for gunshot wound of the abdomen performed in the First Division Hospital, the only ones to his knowledge during the Cuban campaign. All the patients died. The same author says: "I have seen numbers of cases of penetrating wounds of the abdomen in the First and Third Division Hospitals that were on a fair way to recovery without operation before they were sent home on the transport ships." It is to be regretted that he was not specific as to numbers and the ultimate issue; the matter is too important to be casually disposed of. One is not surprised that he should seek and be pleased in finding confirmation of his previously expressed views, "that not infrequently cases of penetrating wounds of the abdomen will recover without active surgical interference." All Dr, Senn's contributions-and they have been marvelously numerous-based upon his observations in the late Cuban war have been a source of much pleasure and information to his readers. It is to be feared his conclusions will prove a serious obstacle to surgical practice, and unfortunately tend to dislodge the well-established opinion that penetrating gunshot wounds of the abdomen require imme. diate laparotomy. This dictum was expressed in formal resolution by the Southern Surgical and Gynecological Association at its meeting in Nashville in 1897.

Dr. W. E. Parker, a volunteer surgeon in the late war, who has had unusually successful experience with gunshot wounds of the abdomen in private and hospital practice, while admitting that 50 per cent. of penetrating gunshot wounds of the abdomen received during the last war recovered without operation, still believes in laparotomy in every case in civil life. His plea for inactivity is based upon the small bullet, the high velocity, the want of facilities for the execution of a technically perfect operation and the empty con- 